\title{
Gender patterns in the contribution of different types of violence to posttraumatic stress symptoms among South African urban youth
}

\author{
Debra Kaminer, Anneli Hardy, Katherine Heath, Jill Mosdell, Umesh Bawa
}

\begin{abstract}
Objective: Identifying the comparative contributions of different forms of violence exposure to trauma sequelae can help to prioritize interventions for polyvictimized youth living in contexts of limited mental health resources. This study aimed to establish gender patterns in the independent and comparative contributions of five types of violence exposure to the severity of posttraumatic stress symptoms among Xhosa-speaking South African adolescents.
\end{abstract}

Method: Xhosa-speaking adolescents $(n=230)$ attending a high school in a low-income urban community in South Africa completed measures of violence exposure and posttraumatic stress symptoms.

Results: While witnessing of community violence was by far the most common form of violence exposure, for the sample as a whole only sexual victimization and being a direct victim of community violence, together with gender, contributed independently to the severity of posttraumatic stress symptoms. When the contribution of different forms of violence was examined separately for each gender, only increased exposure to community and sexual victimization were associated with symptom severity among girls, while increased exposure to direct victimization in both the community and domestic settings were associated with greater symptom severity in boys.

Conclusions: The findings provide some preliminary motivation for focusing trauma intervention initiatives in this community on girls who have experienced sexual abuse compounded by victimization in the community, and boys who have been direct victims of either domestic or community violence. Further research is required to establish whether the risk factors for posttraumatic stress symptoms identified among adolescents in this study are consistent across different communities in South Africa, as well as across other resource-constrained contexts.

The mental health impact of violence exposure on youth appears to be cumulative. The greater the number of traumas experienced, the greater the risk of both internalizing and externalizing psychiatric symptomatology (Finkelhor, Ormrod, \& Turner, 2007; McCart et al., 2007), suggesting that living in contexts of multiple and continuous trauma exposure creates a substantial mental health burden for young 
people. However, among youth exposed to multiple forms of violence across different contexts, or 'polyvictimized youth' (Finkelhor et al., 2007), the association between the overall number of trauma exposures and severity of psychiatric symptoms tells us little about which particular forms of exposure may be most pathogenic, and is therefore of only limited use for guiding specific intervention initiatives.

Although previous research has found that community violence (Fowler, Tompsett, Braciszewski, Jacques-Tiura, \& Baltes, 2009; Okundaye, 2004) and domestic violence (Evans, Davies, \& DiLillo, 2008) are each associated with a range of psychiatric symptomatology among youth, fewer studies have explored the comparative contributions of different forms of violence to mental health outcomes. Since the impact of any one particular form of victimization (such as domestic violence, sexual abuse, or witnessing community violence) may be over-estimated if it occurs in combination with other forms of violence exposure, it is important to explore the comparative contributions to mental health outcomes when different forms of violence exposure are considered simultaneously (Garrido, Culhane, Raviv, \& Taussig, 2010; Turner, Finkelhor, \& Ormod, 2006). This can inform the prioritization of prevention strategies and mental health service delivery in a context of limited economic resources.

Studies that have examined the comparative contributions of different forms of violence exposure among youth have reported mixed findings. Some have found no independent contribution of community violence to internalizing or externalizing symptoms after controlling for the influence of domestic violence (Mrug, Loosier, \& Windle, 2008). Others have found that community violence does predict trauma symptoms even after accounting for the effect of family violence, but that family violence does not independently contribute to symptoms when community violence exposure is considered (Garrido et al., 2010). Still others have reported that both community violence and family violence contribute independently to the severity of psychological symptoms (Hunt, Martens, \& Belcher, 2011; Malik, 2008). In addition, much previous research with children and adolescents has not specifically assessed the impact of sexual violence on traumatic stress symptoms when controlling for other forms of victimization. Where the impact of sexual abuse has been disaggregated from other forms of violence exposure, the findings have been equivocal: the National Survey of Adolescents in the United States found that sexual abuse contributed independently to PTSD even when the impact of physical abuse and witnessed violence were accounted for (Kilpatrick et al., 2003; Macdonald, Kmett Danielson, Resnick, Saunders, \& Kilpatrick, 2010), while a study with African American children and adolescents reported that sexual abuse did not independently predict PTSD when considered together with other forms of victimization (Hunt et al., 2011). All the above studies have emerged from economically developed countries, but there is a dearth of comparable data from low and middle income countries, where rates of violence exposure may be higher, and mental health resources substantially lower. 
Several sources of data suggest that young South Africans grow up in a particularly violent context, even when compared with their counterparts in the United States. The homicide rate in South Africa is five times the global average, and male youth are the most frequent victims (Seedat, Van Niekerk, Jewkes, Suffla, \& Ratele, 2009). In a national prevalence study, 30\% of youth living in major metropolitan centers had been victims of violent crime (Burton, 2006). Further, some studies report that South Africa has one of the highest incidences of rape worldwide (Jewkes \& Abrahams, 2002; South African Institute of Race Relations, 2004), and an analysis of South African police statistics indicates that over $40 \%$ of all reported rapes, and half of all other sexual assaults, have been perpetrated against children (RAPCAN, 2012). Finally, in an epidemiological study of South African adults (Kaminer, Grimsrud, Myer, Stein, \& Williams, 2008), retrospectively reported childhood physical abuse was higher than that reported in similar studies in the United States (Kessler, Sonnega, Bromet, Hughes, \& Nelson, 1995). Taken together, these findings indicate exceptionally high levels of exposure to criminal, sexual and domestic violence among South African youth. Understanding and addressing the impact of violence exposure among youth is therefore a pressing mental health priority in South Africa. However, existing state mental health services for children and adolescents are extremely limited (Lund, Boyce, Flisher, Kafaar, \& Dawes, 2009), and not all youth who are affected by violence can feasibly receive treatment. Furthermore, resources for violence prevention initiatives are constrained. It is therefore important to identify those forms of violence exposure that pose the greatest risk to the mental health of young South Africans.

While it is apparent that cumulative trauma exposure as well as specific forms of violence are associated with a range of internalizing and externalizing symptomatology among South African youth (Seedat, Nyamai, Njenga, Vythilingum, \& Stein, 2004; Shields, Nadasen, \& Pierce, 2008, 2009; Suliman et al., 2009; Ward, Martin, Theron, \& Distiller, 2007), the comparative contributions of particular forms of violence are less clear. One previous study reported that both community violence and childhood abuse contributed independently to PTSD symptoms in South African adolescents (Fincham, Korthals Altes, Stein, \& Seedat, 2009), while another found that both witnessing and direct victimization in the community contributed independently to psychological distress (Shields et al., 2009). However, a more fine grained analysis of how different forms of direct and indirect violence contribute to mental health outcomes would help to further direct targeted interventions for polyvictimized South African youth.

The present study aimed to explore the comparative contributions of five different forms of violence (witnessing physical violence in the community, being a victim of physical violence in the community, witnessing physical violence in the home, being a victim of physical violence in the home, and sexual victimization) to posttraumatic stress symptoms among Xhosa-speaking adolescents in a low-income urban community in South Africa. Since previous research in both the United States (Breslau, Wilcox, Storr, Lucia, \& Anthony, 2004) and South Africa (Fincham et al., 2009; Seedat, van Noord, Vythilingum, Stein, \& Kaminer, 2000) has reported distinct gender patterns in types of trauma exposure and in the associated risk for 
PTSD among adolescents, the study will also consider the impact of different forms of violence on boys and girls separately.

\section{Method}

\section{Sample}

Two hundred and thirty learners from a high school in Langa, Cape Town, participated in the study. Langa is one of the country's oldest townships, created just after World War I. It was designated for 'Black Africans' under apartheid, and the community continues to reflect this profile. The first language of most families in the Langa community is Xhosa (Statistics South Africa, 2003). Due to the socioeconomic legacy of apartheid, many black South Africans, including many Xhosa-speaking communities such as that residing in Langa, continue to live in conditions of poverty.

The sample comprised all learners in Grades 9-11 who were present in their classrooms on the day the study was administered. The sample included 138 (60\%) girls and 92 (40\%) boys, ranging in age from 14 to 21 years of age $(M=17.45 ; S D=$ 1.599).

\section{Instruments}

Exposure to violence. An adapted version of the 39-item Child Exposure to Community Violence self-report scale (CECV; Amaya-Jackson, 1998), translated into Xhosa, was used to assess exposure to different forms of violence within the home and the community, through witnessing, and direct victimization. The CECV has demonstrated good internal consistency and test-retest reliability (Fehon, Grilo, \& Lipschitz, 2001), and in previous studies with South African samples excellent internal consistency has been reported (Fincham et al., 2009).

For the current study, the items were adapted slightly to assess exposure to various forms of violence both at home and in the neighborhood, in cases where the original scale enquired about exposure in one site only. Items that measured perpetration of violence, rather than victimization, were excluded, as were items that assessed experiences other than violence (for example, witnessing drug deals in the community). There were 27 items in total.

The Likert-type response scale for the original CECV has 5 points, indicating the number of times each form of violence has been experienced by the participant (ranging from 'never' to 'more than 10 times'). However, some researchers have questioned whether it is possible to obtain reliable retrospective estimates of the exact frequency of trauma exposure in contexts of chronic violence (Wolfe, 1995; Wolfer, 1999). Bearing these concerns in mind, a simplified three-point response scale was used to assess frequency of exposure to each type of violence ('never', 'a few times' and 'many times'), with high scores indicating greater frequency of exposure.

The adapted and translated 27-item version used in this study had good internal consistency with a Cronbach alpha coefficient of .86. Theoretical subscales of the 
CECV were composed, differentiating between community violence victimization (CVV; 5 items), community violence witness (CVW; 8 items), domestic violence victimization (DVV; 5 items), domestic violence witness (DVW; 5 items), and sexual victimization (SV; 4 items). The Cronbach alpha coefficients for these subscales were, respectively, $.72, .85, .60, .60$, and .77 . These sub-scale alphas were not improved by removal of any of the items from the sub-scales. Sub-scale composite scores were derived by summing all the items within each sub-scale.

Posttraumatic stress disorder. An adapted version of the Child PTSD Checklist (Amaya-Jackson, McCarthy, Newman, \& Cherney, 1995), translated into Xhosa, was used to assess symptoms of posttraumatic stress disorder. Of the original 28 items, 21 were retained that assess core symptoms of PTSD. The original 4-point response scale (ranging from 'not at all' to 'all the time") could not be directly translated into Xhosa, and a 3 -point scale ( $0=$ 'never', 1 = 'some days', 2 = 'every day') was therefore used, with high scores indicating greater frequency of symptoms. The original scale has demonstrated excellent internal consistency, good test-retest reliability and good convergent validity (March, Amaya-Jackson, Terry, \& Costanzo, 1997), while excellent internal consistency has been reported for South African samples also (Fincham et al., 2009). The adapted and translated version used in this study demonstrated good internal validity, with a Cronbach alpha coefficient of .87. The total possible score on the adapted scale is 42 .

\section{Procedure}

To translate the adapted CECV and posttraumatic stress symptom scales from English into Xhosa, established translation and back-translation procedures were used to ensure semantic equivalence (Bontempo, 1993; Brislin, 1986).

In order to recruit participants for the study, a week prior to the study an information letter and an informed consent letter were sent to the parents of all the children in all the Grade 9, Grade 10 and Grade 11 classes at the school. Less than 5\% of parents refused to give consent for participation. Written assent for participation was obtained from participants on the day of administration. Participation in the study was voluntary, and the purpose and value of the study were explained to parents and participants as part of the consent/assent process. In the few cases where informed consent and/or assent were not obtained, the adolescent was provided with an alternative school task to complete in the classroom during administration. Participants were not remunerated for their participation.

Instruments were administered to the participants in their classrooms during a $45 \mathrm{~min}$ lesson period. Due to varying levels of literacy in this sample (established through discussions with class teachers prior to administration of the study), instructions, questionnaire items and response options were read to each class verbally by a Xhosa-speaking research assistant, with time provided for all participants to mark down their response to each item (in the form of an ' $X$ ') before the next item was read out. 


\begin{tabular}{|c|c|c|c|c|c|c|}
\hline & \multicolumn{3}{|c|}{ Original sample } & \multicolumn{3}{|c|}{ After imputation } \\
\hline & $N$ & Mean & SD & $N$ & Mean & SE \\
\hline PTSD & 192 & 16.93 & 7.013 & 230 & 17.23 & .476 \\
\hline CECV & 196 & 13.20 & 6.980 & 230 & 13.58 & .482 \\
\hline $\operatorname{CVV}(8)$ & 224 & 1.71 & 1.920 & 230 & 1.75 & .128 \\
\hline CVW (5) & 217 & 7.85 & 3.939 & 230 & 7.86 & .256 \\
\hline $\operatorname{DVV}(5)$ & 221 & 1.53 & 1.694 & 230 & 1.60 & .115 \\
\hline DVW (5) & 221 & 1.77 & 1.661 & 230 & 1.80 & .111 \\
\hline SV (4) & 227 & .56 & 1.227 & 230 & .57 & .082 \\
\hline
\end{tabular}

Note: CECV - Child Exposure to Community Violence scale, CVV - community violence victimization, CVW - community violence witness, DVV - domestic violence victimization, DVW - domestic violence witness, SV - sexual victimization; number of items in parentheses.

The same research assistant administered the questionnaires to all the classes. Teachers remained present in the class during administration but did not participate in the administration. Desks were spaced out in order to ensure adequate privacy for each participant.

The CECV was administered first. Once this was completed, participants were asked to choose the item on the CECV that had been most upsetting for them, and to answer the subsequent questions on the Child PTSD Checklist in relation to that particular event.

\section{Data analysis}

To explore the prevalence of different forms of violence exposure in the sample, the scaled CECV items were dichotimized into 'never' and 'at least once' (the latter category combined the second and third response ratings). The association between gender and exposure to each of the 27 specific forms of violence assessed in the CECV was examined by the Fisher's Exact test.

Gender patterns in types of violence exposure as measured by the theoretical subscale scores and in the severity of posttraumatic stress symptoms were investigated using the independent samples $t$-test. The association between exposure to different forms of violence and posttraumatic stress was analyzed using Pearson product-moment correlation coefficients as well as multiple linear regression analysis. Gender was included in the regression analysis as a predictor. Gender was also investigated as a moderator of the relationship between the different forms of violence exposure and posttraumatic stress symptoms. Separate multiple linear regression models for boys and girls were also analyzed. Data analysis was performed using PASW Statistics (SPSS) version 19.0.0 for Windows (SPSS Inc., 2011).

\section{Missing data}

Item nonresponse occurred on both the scales. Based on listwise deletion, 37 (16.1\%) cases did not have complete data on the CECV scale, and 38 (16.5\%) cases did not have complete data on the PTSD checklist. The patterns of missing data suggest that item nonresponses were not missing completely at random (MCAR). 
Item nonresponse was handled by imputing missing values using the two-way multiple imputation with error method (Method TW; Little \& Su, 1989). Method TW imputation was carried out using PASW Statistics (SPSS) for Windows version 19 (Van Ginkel, Sijtsma, Van Der Ark, \& Vermunt, 2010). Five imputed data sets were created and statistical analyses were performed on the five imputed datasets separately. Method TW was applied to each scale separately. Cronbach alpha coefficients for each scale, and for the subscales of the CECV, were obtained as the mean of the five alpha values obtained from the five imputed data sets. Correlation coefficients were obtained as the mean of the five $r$-values from the five imputed data sets. $R, R$-squared, adjusted $R$-squared, and the square semipartial correlation coefficients from the regression analyses were averaged across the five imputed data sets. Parameter estimates were combined using the rules of Rubin (1987).

\section{Results}

\section{Descriptive statistics}

Table 1 reports the descriptive statistics for the original sample as well as the combined results (after imputation) from the five imputed data sets for the posttraumatic stress symptom severity score, the CECV total score and the CECV subscale scores.

The prevalence of exposure to each of the 27 items of the CECV, using the dichotomized scores, is reported in Table 2. Experiences of witnessing community violence were the most frequently reported type of violence exposure in the sample: within their neighborhood, almost all participants (98.7\%) had heard gunshots, 93.9\% had witnessed someone being beaten, $78 \%$ had witnessed someone pulling a knife on another person, and 40.3\% had actually witnessed someone being killed.

Experiences of domestic violence were less pervasive, but nonetheless common. A third of the sample (33.5\%) had witnessed adults in the home hit each other, while $47.8 \%$ had been beaten by a family member. Reports of sexual victimization in or outside the home were the least common.

Cross tabulations of the dichotomized CECV items with gender were generated from the original data as pair wise deletion results in at most 6 cases being excluded. Significant gender differences are indicated in Table 2. Proportions of boys' and girls' exposure to specific violence types were very similar on all but seven of the CECV items. A significantly larger proportion of boys (57, 63\%) reported having witnessed a shooting in their neighborhood compared to girls $(63,46 \% ; p=.015, \varnothing$ $=.163)$, a significant larger proportion of boys $(51,56 \%)$ reported having seen a dead body around their neighborhood compared to girls $(57,42 \% ; p=.042, \varnothing=$ .142), and a slightly larger, but statistically significant, proportion of boys $(61,67 \%)$ also reported having seen somebody pull a gun on another person in their neighborhood compared to girls $(73,53 \% ; p=.04, \varnothing=.14)$. Regarding direct victimization in the community, boys were significantly more likely than girls to report being threatened to be beaten up (boys $-57,62.6 \%$; girls $-64,47.1 \%$; $p=$ 
$.03, \varnothing=.153$ ) or being threatened to be shot or stabbed (boys $-28,30.4 \%$; girls 26, $18.8 \% ; p=.056, \varnothing=.134)$.

Table 2

Prevalence of exposure to specific violence types.

\begin{tabular}{|c|c|c|}
\hline CECV item & Valid N & One or more times \\
\hline \multicolumn{3}{|l|}{ Witnessing of community violence } \\
\hline Heard guns being shot & 229 & $226(98.7 \%)$ \\
\hline Seen somebody being beaten up in neighborhood & 230 & $216(93.9 \%)$ \\
\hline Seen somebody get stabbed in neighborhood & 230 & $163(70.9 \%)$ \\
\hline Seen somebody get shot in neighborhood ${ }^{a}$ & 228 & $120(52.6 \%)$ \\
\hline Seen a dead body around neighborhood ${ }^{\mathrm{a}}$ & 228 & $108(47.4 \%)$ \\
\hline Seen somebody pull a gun on another person in neighborhood ${ }^{\mathrm{a}}$ & 229 & $134(58.0 \%)$ \\
\hline Seen somebody pull a knife on (or show a knife to) another person in neighborhood & 227 & $177(78.0 \%)$ \\
\hline Seen someone being killed by another person in neighborhood & 224 & $90(40.2 \%)$ \\
\hline \multicolumn{3}{|l|}{ Community violence victimization } \\
\hline Threatened to be beat up by someone outside your family ${ }^{\mathrm{a}}$ & 227 & $121(53.3 \%)$ \\
\hline Actually been beaten up by someone outside your family & 228 & $82(36.0 \%)$ \\
\hline Someone outside your family threatened to kill you & 227 & $33(14.5 \%)$ \\
\hline Someone outside your family threatened to shoot or stab you ${ }^{\mathrm{a}}$ & 230 & $54(23.5 \%)$ \\
\hline Been pinched, kicked or locked up by someone outside your family & 229 & $40(17.5 \%)$ \\
\hline \multicolumn{3}{|l|}{ Witnessing domestic violence } \\
\hline Heard grown-ups in your home yell at each other & 230 & $156(67.8 \%)$ \\
\hline Seen a gun in your home & 227 & $31(13.7 \%)$ \\
\hline Seen grown-ups in your home hit each other & 230 & $77(33.5 \%)$ \\
\hline Seen someone in your home get shot or stabbed & 227 & $25(11.0 \%)$ \\
\hline Seen a family member pull a knife or gun on another family member ${ }^{a}$ & 226 & $35(15.5 \%)$ \\
\hline \multicolumn{3}{|l|}{ Domestic violence victimization } \\
\hline Threatened to be beat up by a family member & 229 & $74(32.3 \%)$ \\
\hline Actually been beaten up by a family member & 224 & $107(47.8 \%)$ \\
\hline Someone in your family threatened to kill you & 229 & $26(11.4 \%)$ \\
\hline Someone in your family threatened to shoot or stab you & 229 & $28(12.0 \%)$ \\
\hline Been pinched, kicked or locked up by a family member & 228 & $58(25.4 \%)$ \\
\hline \multicolumn{3}{|l|}{ Sexual victimization } \\
\hline Someone in your family ever touched you or kissed you in a way that made you feel uncomfortable ${ }^{a}$ & 230 & $24(10.4 \%)$ \\
\hline $\begin{array}{l}\text { Someone outside your family ever touched you or kissed you in a way that made you feel } \\
\text { uncomfortable way that made you feel uncomfortable }\end{array}$ & 230 & $42(18.3 \%)$ \\
\hline $\begin{array}{l}\text { Someone in your family ever made you do something with your private parts or with their private } \\
\text { parts that you did not want to do }\end{array}$ & 229 & $18(7.9 \%)$ \\
\hline $\begin{array}{l}\text { Someone outside your family ever made you do something with your private parts or with their } \\
\text { private parts that you did not want to do }\end{array}$ & 228 & $28(12.3 \%)$ \\
\hline
\end{tabular}

a Indicates items on which the proportion of boys and girls differed significantly.

With regard to domestic violence, a significantly larger proportion of boys (28, $30.8 \%)$ compared to girls $(7,5.2 \%)$ reported witnessing a family member pulling a knife or gun on another family member $(p<.001, \varnothing=.347)$. With regard to sexual victimization, a significantly larger proportion of boys $(16,17.4 \%)$ compared to girls $(8,5.8 \%)$ reported that someone in their family had touched or kissed them in a way that made them feel uncomfortable $(p=.007, \varnothing=.186)$. Similarly, a significantly larger proportion of boys $(13,14.1 \%)$ compared to girls $(5,3.6 \%)$ reported that someone in the family made them do something with their private parts that they did not want to do $(p=.005, \varnothing=.191)$. Similar proportions of boys and girls endorsed the items assessing coercive sexual experiences outside the family.

Boys and girls were compared on severity of symptoms of posttraumatic stress, the CECV total score and its subscale scores using the independent samples $t$-test. Results of these comparisons between boys and girls are presented in Table 3 . There was no significant difference in scores for boys and girls except for total CECV and DVW. Boys had a significantly higher mean value on both scores compared to girls. 
Gender differences in PTSD and exposure to violence.

\begin{tabular}{|c|c|c|c|c|c|c|c|c|}
\hline & Sex & $N$ & Mean & SE & Mean diff & SE diff & $t(\mathrm{df})$ & $p$-Value \\
\hline PTSD & $\begin{array}{l}\text { Boys } \\
\text { Girls }\end{array}$ & $\begin{array}{r}92 \\
138\end{array}$ & $\begin{array}{l}16.42 \\
17.78\end{array}$ & $\begin{array}{l}.757 \\
.609\end{array}$ & -1.356 & .969 & $-1.399(225.544)$ & .163 \\
\hline CECV & $\begin{array}{l}\text { Boys } \\
\text { Girls }\end{array}$ & $\begin{array}{r}92 \\
138\end{array}$ & $\begin{array}{l}14.76 \\
12.80\end{array}$ & $\begin{array}{l}.807 \\
.590\end{array}$ & 1.967 & .978 & $2.011(225.163)$ & .046 \\
\hline cVV & $\begin{array}{l}\text { Boys } \\
\text { Girls }\end{array}$ & $\begin{array}{r}92 \\
138\end{array}$ & $\begin{array}{l}2.00 \\
1.60\end{array}$ & $\begin{array}{l}.198 \\
.168\end{array}$ & .414 & .261 & $1.585(225.455)$ & .114 \\
\hline CVW & $\begin{array}{l}\text { Boys } \\
\text { Girls }\end{array}$ & $\begin{array}{r}92 \\
138\end{array}$ & $\begin{array}{l}8.28 \\
7.57\end{array}$ & $\begin{array}{l}.397 \\
.333\end{array}$ & .709 & .521 & $1.361(225.028)$ & .175 \\
\hline DVV & $\begin{array}{l}\text { Boys } \\
\text { Girls }\end{array}$ & $\begin{array}{r}92 \\
138\end{array}$ & $\begin{array}{l}1.60 \\
1.60\end{array}$ & $\begin{array}{l}.173 \\
.153\end{array}$ & .010 & .235 & $.043(223.082)$ & .966 \\
\hline DVW & $\begin{array}{l}\text { Boys } \\
\text { Girls }\end{array}$ & $\begin{array}{r}92 \\
138\end{array}$ & $\begin{array}{l}2.09 \\
1.60\end{array}$ & $\begin{array}{l}.195 \\
.130\end{array}$ & .498 & .225 & $2.214(225.447)$ & .028 \\
\hline SV & $\begin{array}{l}\text { Boys } \\
\text { Girls }\end{array}$ & $\begin{array}{r}92 \\
138\end{array}$ & $\begin{array}{l}.77 \\
.44\end{array}$ & $\begin{array}{l}.150 \\
.092\end{array}$ & .336 & .176 & $1.913(225.883)$ & .057 \\
\hline
\end{tabular}

Note: CECV - Child Exposure to Community Violence scale, CVV - community violence victimization, CVW - community violence witness, DVV - domestic violence victimization, DVW - domestic violence witness, SV- sexual victimization.

\section{Relation between types of violence exposure and symptoms of posttraumatic stress}

The Pearson product-moment correlation coefficients between types of violence exposure and the severity of posttraumatic stress symptoms suggest that symptoms showed a moderate positive correlation with total CECV score $(r=.370)$, CVV $(r=.375)$, DVV $(r=.326)$ and SV $(r=.340)$, with greater severity of symptoms of posttraumatic stress associated with higher levels of exposure on each of the types of violence exposure. The association between the severity of posttraumatic stress symptoms and the witnessing violence exposure factors was small $(r<.2)$.

Multiple regression was performed between severity of posttraumatic stress symptoms as the dependent variable and CVV, CVW, DVV, DVW, SV and gender as the independent variables. Collinearity statistics suggested possible issues of multicolinearity, though no Variance Inflation Factor (VIF) value greater than two or Condition Index greater than 15 was reported. Inspection of the residual plots and Mahalanobis distance suggested no serious violation of the assumptions of normality, linearity, outliers, and homoscedasticity. The regression was significantly different from zero on all analyses performed on the five imputed data sets. Table 4 displays the unstandardized regression coefficients, the squared semipartial correlations, $R^{2}$, and adjusted $R^{2}$. This model explained $21 \%$ (19\% adjusted) altogether of the variability in severity of posttraumatic stress symptoms. Only two of the victimization factors (CVV, SV) as well as gender, were statistically significant. SV and CVV were the most important predictors, followed by gender, as indicated by the squared semipartial correlations. With regard to gender, the result suggests that when all the other predictors are held constant, on average girls tend to present with greater severity of posttraumatic stress symptoms compared to boys.

In addition to examining whether gender contributes independently to posttraumatic stress symptoms when considered together with different forms of violence exposure, moderated regression analyses were performed to evaluate whether gender alters the direction or strength of the relation between each of 
the different forms of violence and the severity of posttraumatic stress symptoms. Five models were generated, one for each of the different violence exposure subtypes. Regression analysis was performed with posttraumatic stress symptoms as the dependent variable and one of the violence exposure subtypes together with gender as the independent variables. The moderation effect was evaluated by an interaction term between gender and the violence exposure subtype in the regression model. Inspection of separate lines of best fit for boys and girls in scatterplots of posttraumatic stress symptoms against each of the violence exposure subtypes showed no obvious deviation from parallelism. The results suggest that gender has no moderating effect on the relation between posttraumatic stress symptoms and any of the different forms of violence.

\begin{tabular}{|c|c|c|c|c|c|}
\hline & $B$ & $\mathrm{SE}$ & $t$ & p-Value & $s r^{2}$ \\
\hline Intercept & 12.061 & 1.158 & 10.413 & $<.001$ & \\
\hline $\mathrm{CVV}$ & .771 & .284 & 2.714 & .007 & .029 \\
\hline CVW & .134 & .120 & 1.112 & .266 & .004 \\
\hline DVV & .510 & .320 & 1.592 & .111 & .01 \\
\hline DVW & .003 & .310 & .010 & .992 & $<.01$ \\
\hline SV & 1.133 & .403 & 2.812 & .005 & .029 \\
\hline Sex & 2.158 & .882 & 2.447 & .014 & .021 \\
\hline
\end{tabular}

DVV - domestic violence victimization, DVW - domestic violence witness, SV - sexual victimization.

Table 5

Multiple regression of different forms of violence exposure on severity of PTSD symptoms for girls.

\begin{tabular}{lrrrrr}
\hline & $B$ & SE & \multicolumn{1}{c}{$t$} & $p$-Value \\
\hline Intercept & 15.076 & 1.241 & 12.150 & $<.001$ & .008 \\
CVV & .876 & .333 & 2.634 & .809 & .041 \\
CVW & .037 & .154 & .242 & .473 & $<.01$ \\
DVV & .291 & .406 & .718 & .859 & $<.01$ \\
DVW & -.077 & .431 & -.177 & .008 & .041 \\
SV & 1.551 & .589 & 2.632 & .008 \\
\hline
\end{tabular}

$R-.446 ; R^{2}-.198 ;$ adj $R^{2}-.168 ; s r^{2}-$ squared semipartial correlation.

Note: CVV - community violence victimization, CVW - community violence witness, DVV - domestic violence victimization, DVW - domestic violence witness, SV - sexual victimization.

There is thus not sufficient evidence in the current study to suggest that the effect of each of the different forms of violence on the severity of posttraumatic stress symptoms differs systematically as a function of gender, when the violence subtypes are considered separately.

To explore the details of the influence of different forms of violence for each gender when all violence types are considered simultaneously, multiple regression analysis was performed separately for boys and girls, with severity of posttraumatic stress symptoms as the dependent variable and CVV, CVW, DVV, DVW, and SV entered simultaneously as the independent variables. The regression for girls was significantly different from zero on all analyses performed on the five imputed data sets. Inspection of the residual plots, Mahalanobis distance, Tolerance, and VIF values suggested no serious violation of the assumptions of collinearity, normality, linearity, outliers, and homoscedasticity. Table 5 displays the unstandardized regression coefficients, the squared semipartial correlations, $R^{2}$, and adjusted $R^{2}$. Altogether, $20 \%$ (17\% adjusted) of the variability in severity of posttraumatic stress symptoms in girls was predicted by knowing the scores on 
these exposure to violence predictors. Only CVV and SV were statistically significant, with both factors being equally important as indicated by the squared semipartial correlations, while other forms of violence exposure did not increase the utility of the model.

Tolerance and VIF values suggested multicolinearity in the regression for boys. CVV (VIF $=2.735$ ) was identified as the most collinear variable followed by DVV (VIF = 2.098) and DVW (VIF = 1.724). Although the model was significant, none of the CECV factors showed significance on the $t$-test. The CVV and DVV items were combined into one score for violent victimization (VV) to deal with the collinearity issue (Tabachnick \& Fidell, 2007). Multiple regression was performed between severity of posttraumatic stress symptoms as the dependent variable and VV, CVW, DVW, and SV as the independent variables. The regression for boys was significantly different from zero on all analyses performed on the five imputed data sets. Inspection of the residual plots, and Mahalonobis distance suggested no serious violation of the assumptions of normality, linearity, outliers, and homoscedasticity. Tolerance and VIF values were all within the acceptable range with no VIF values greater than two suggesting no violation of the assumption of collinearity with the VV subscale score. Table 6 presents the unstandardized regression coefficients, the squared semipartial correlations, $R^{2}$, and adjusted $R^{2}$. Altogether, $24 \%$ (21\% adjusted) of the variability in severity of posttraumatic stress symptoms in boys was predicted by knowing the scores on these predictors. VV was the only statistically significant predictor in the model. The model suggests that greater exposure to victimization in both the community and domestic setting is associated with greater severity of posttraumatic stress symptoms in boys, but that other forms of violence exposure do not contribute anything further to the prediction of posttraumatic stress symptoms.

\section{Discussion}

Community violence exposure (including witnessing weapons violence and dead bodies, and being assaulted with a weapon) appears to be entirely normative for this sample of Xhosa-speaking youth in a low-income urban community in South Africa. This is consistent with reports that homicide rates in the Western Cape region of South Africa, where the sample resides, are the second highest in the country (South African Institute of Race Relations, 2011), in a nation which appears to have the highest homicide rate in the world (Seedat et al., 2009). Although less prevalent than community violence, domestic violence was nevertheless common in this sample.

\begin{tabular}{|c|c|c|c|c|c|}
\hline & B & SE & $t$ & p-Value & $s r^{2}$ \\
\hline VV & .669 & .268 & 2.494 & .013 & .051 \\
\hline CVW & .258 & .195 & 1.322 & .186 & .015 \\
\hline DVW & .210 & .465 & .451 & .652 & $<.01$ \\
\hline SV & .732 & .554 & 1.320 & .187 & .014 \\
\hline
\end{tabular}

$R-.491 ; R^{2}-.241$; adj $R^{2}-.206 ; s r^{2}$ - squared semipartial correlation.

Note: $\mathrm{VV}$ - domestic or community violence victimization; CVV-community violence victimization, CVW- community violence witness, DVV - domestic violence victimization, DVW - domestic violence witness, SV- sexual victimization. 
Sexual victimization was reported by only a minority of participants but, as with most research on sexual coercion, this is likely to be an under-representation (Jewkes \& Abrahams, 2002).

Some gender differences in exposure to violence were apparent. The finding that boys are more likely than girls to have been exposed to severe forms of community violence, especially that involving weapons, is consistent with much previous research (Lambert, Ialongo, Boyd, \& Cooley, 2005) and may to some extent reflect the greater involvement of adolescent males in gang-related activities. While some existing research reports no gender difference in rates of witnessing domestic violence (Turner et al., 2006), in our sample boys appeared to be more likely than girls to witness violence between adults in the home. Given that previous international research consistently reports higher rates of sexual victimization among girls (Finkelhor, Ormrod, Turner, \& Hamby, 2005), the higher prevalence of familial sexual coercion reported by boys in this sample compared with girls was particularly surprising. This result may reflect some misinterpretation by participants of the meaning of the translated items assessing sexual abuse, may indicate a higher degree of stigmatization related to disclosing sexual abuse of girls as compared to boys, or may have been influenced by culture-specific experiences such as ritual genital circumcision among Xhosa boys. However, previous South African research has similarly reported a slightly higher prevalence of sexual abuse among boys compared with girls (Madu \& Peltzer, 2000), suggesting that in some South African communities boys may be as or more vulnerable to sexual victimization than girls.

Zero order correlations indicated that greater exposure to each type of direct victimization had a significant relationship with the severity of posttraumatic stress symptoms, while witnessing of violence did not. However, when the contribution of all violence types was considered simultaneously together with gender for the sample as a whole, only sexual victimization, direct victimization in the community and gender contributed independently to posttraumatic stress symptoms. When posttraumatic stress symptoms among girls was examined separately from boys, sexual victimization and victimization in the community were again the only significant victimization types. In the separate regression model for boys, both witnessing of violence and sexual assault failed to contribute significantly to the prediction of posttraumatic stress symptoms once combined exposure to community and domestic victimization had been accounted for, however high levels of multicollinearity prevented a more careful examination of the independent contributions of community and domestic victimization.

While the finding that females are more at risk for posttraumatic stress symptoms is in line with much previous research (Breslau, 1998; Kessler et al., 1995), several other aspects of our findings require further investigation and understanding.

Firstly, our results are inconsistent with some previous research reporting that witnessing violence independently predicts posttraumatic stress symptoms 
beyond the variance accounted for by direct victimization (Zinzow et al., 2009). For our sample as a whole, and for both boys and girls separately, only direct victimization made a significant independent contribution to the severity of posttraumatic stress symptoms. Although direct comparison between our community sample and the national probability sample used by Zinzow et al. (2009) is methodologically limited, it is possible that the much higher levels of witnessing violence reported in our sample may contribute to a desensitization effect for witnessed violence. However, in a previous South African study with a younger and more culturally diverse sample, Shields et al. (2009) reported that both witnessed and direct victimization contributed independently to posttraumatic stress symptoms. It is therefore possible that the desensitization effect for witnessing violence may be more specific to Xhosa adolescents due to particular contextual or cultural factors. For example, an ethnographic study of the morality of youth living in Langa has identified particular constructions of right and wrong, and rules about acceptable behaviour, that are rooted in a combination of partial-parenting, partial-schooling and pervasive poverty, and which may serve to minimize the impact of ambient witnessed violence on posttraumatic stress symptoms among adolescents (Swartz, 2009). Given that witnessing violence appears to be part of daily experience for many South African youth, this possibility requires further investigation. It should also be noted that the witnessing of community violence sub-scale contained some high frequency items, and this restricted range of variability may have restricted the ability to detect significant correlations between witnessing of community violence and posttraumatic stress symptoms. However, removal of these items from the sub-scale would have lowered the internal consistency of the sub-scale.

Secondly, although rates of reported sexual abuse in our sample were lower than rates of other forms of violence exposure, and although items assessing sexual abuse were endorsed more often by boys than girls, this form of exposure appears to confer a high risk for posttraumatic stress symptoms among girls in this community, even when other forms of co-occurring violence exposure are accounted for. The National Survey of Adolescents in the United States similarly found that sexual violence contributed independently to risk for PTSD when other forms of violence are accounted for, but in that study witnessing violence carried a higher risk (Kilpatrick et al., 2003; MacDonald et al., 2010). By contrast, Hunt et al. (2011) reported that child sexual abuse did not enhance the prediction of PTSD symptom severity among African American children and adolescents after accounting for the influence of other forms of violence exposure. Further research on the independent and comparative effects of sexual violence among poly-victimized youth in South Africa and elsewhere would be valuable.

Thirdly, the independent contribution of community violence but not domestic violence to posttraumatic stress symptoms in our sample as a whole, and for girls separately, bears further investigation. This finding does not support those of Mrug et al. (2008), who reported that community violence did not contribute independently to psychological outcomes once domestic violence was considered, or Malik (2008), who found that both community and domestic violence 
independently contributed to psychological functioning. Unfortunately, direct comparison with these two studies is limited by their use of more generalized, rather than PTSD-specific, psychological outcome measures. Even comparison with studies that have used PTSD outcome measures is limited by differing ways of operationalizing community violence exposure, as well as sampling differences. Garrido et al.'s (2010) study with younger American children found that witnessing community violence independently predicted PTSD severity, while victimization in the home did not, but the study did not assess the impact of direct victimization in the community. In addition, all the children in Garrido et al.'s study had been removed from their homes due to abuse and neglect, implying a more limited range of variability in exposure to domestic violence compared with the current sample. Some research in the United States (Hunt et al., 2011) and in South Africa (Fincham et al., 2009) has found that both community violence and domestic violence contribute independently to the severity of PTSD symptoms, but these studies did not disaggregate the contributions of indirect and direct exposure to violence. The findings of our study suggest that, in contexts of polyvictimization of youth, this kind of finer disaggregation may be valuable for further unpacking the specific forms of violence exposure that increase risk for posttraumatic stress symptoms and other sequelae. With regard to the gendered profile of risk for posttraumatic stress symptoms among polyvictimized youth, our study was not able to discriminate the comparative risks that direct victimization in the community and in the home place on adolescent boys, and this requires further exploration.

Finally, it should be noted that the mean score on the adapted posttraumatic stress scale was 17.23 out of a maximum possible score of 42. Establishment of a clinically significant cut-off score for PTSD in this sample would require comparison with a gold standard clinical assessment instrument for PTSD, such as the CAPS-C (Blake et al., 1995). However, the positioning of the mean score towards the mid-point of the scale suggests that, on average, levels of posttraumatic stress in this highly violence-exposed sample are not very high. This may be indicative of a fairly high level of resilience within this sample. On the other hand, it is possible that other psychological outcomes besides posttraumatic stress symptoms (such as depression or aggression) may be more strongly associated with high levels of violence exposure across multiple sites.

The findings of the present study need to be considered in the light of some methodological limitations. The Xhosa-language posttraumatic stress symptom inventory demonstrated good internal consistency but still requires validation against other clinical instruments. This implies that caution should be exercised in interpreting and generalizing the results of this study. However, this needs to be weighed against the potential limitations to validity of assessing clinical symptoms in a language other than the participants' first language.

A second limitation relates to the 3-point response scale used on both instruments. A simulation study conducted on the optimal number of response categories with reliability and factorial validity as the criterion demonstrated that fewer number of response categories resulted in lower variability and consequently resulted in lower 
internal consistency as measured by the Cronbach alpha (Lozano, García-Cueto, \& Muñiz, 2008). Inspection of histograms of the posttraumatic stress scale items suggested a concentration in the middle response category, and the use of a 3-point response scale here may therefore have resulted in reduced variability and consequently lower reliability. By contrast, CECV items did not show so much the concentration on the middle category as generally expected of 3-point response scales. In addition, the response options (e.g. "a few times" and "many times") are not precise and entail some degree of subjective interpretation. At the same time, in contexts of chronic violence, the possibility of reliable recall of exact number of exposures has been questioned (Wolfe, 1995; Wolfer, 1999), and more specific response categories for frequency may also result in unreliable reporting. Finally, although seating arrangements in the classrooms attempted to maximize privacy for participants, it is possible that the presence of teachers in the classroom during administration, and concerns about privacy from other learners, may have influenced the endorsing of items.

\section{Conclusion}

Bearing in mind the above caveats, the findings of this study highlight the frequency and severity of exposure to violence across different life domains among Xhosaspeaking youth in this South African community. Our results further suggest that, in a context of multiple violence exposure, more direct forms of violence exposure may pose a particularly high risk for posttraumatic stress symptoms among both male and female adolescents. Screening for exposure to direct victimization, through the use of brief trauma exposure questionnaires during Life Orientation classes (which are part of school curriculum in South Africa and many other countries), or by harnessing teachers' knowledge about the home and neighborhood experiences of learners in their class, could assist to identify boys and girls who may require further screening for posttraumatic stress symptoms and possible clinical referral.

In a context of limited mental health resources, the current findings provide some preliminary motivation to consider focusing South African trauma intervention initiatives in this community on girls who have experienced sexual abuse compounded by victimization in the community, and on boys who have been direct victims of either domestic or community violence. However, given the limitations of cross-sectional research designs in delineating the psychological effects of previous trauma exposure, future longitudinal research is required in order to further explore the comparative psychological impact of different types of violence for adolescents of both genders. In addition, further research is required to establish whether the risk factors for posttraumatic stress symptoms identified among adolescents in this study are consistent across different communities in South Africa, as well as across other resource-constrained contexts. 


\section{References}

Amaya-Jackson, L. (1998). Child's exposure to violence checklist. Durham, NC: Trauma Evaluation, Treatment and Research Programme, Centre for Child and Family Health.

Amaya-Jackson, L., McCarthy, G., Newman, E., \& Cherney, M. (1995). Child PTSD Checklist. Unpublished instrument. Department of Psychiatry, Duke University: Durham, NC.

Blake, D. D., Weathers, F. W., Nagy, L. M., Kaloupek, D. G., Gusman, F. D., Charney, D. S., et al. (1995). The development of a clinicianadministered PTSD scale. Journal of Traumatic Stress, 8(1), 75-90.

Bontempo, R. (1993). Translation fidelity of psychological scales: An itemresponse theory analysis of an individualism-collectivism scale. Journal of Cross- Cultural Psychology, 24(2), 149-166.

Breslau, N. (1998). Epidemiology of trauma and posttraumatic stress disorder. In R. Yehuda (Ed.), Review of psychiatry (pp. 1-30). Washington, DC: American Psychiatric Association.

Breslau, N., Wilcox, H. C., Storr, C. L., Lucia, V. C., \& Anthony, J. V. (2004). Trauma exposure and posttraumatic stress disorder: a study of youths in urban America. Journal of Urban Health: Bulletin of the New York Academy of Medicine, 81, 530-544.

Brislin, R. W. (1986). The wording and translation of research instruments. In W. J. Lonner, \& J. W. Berry (Eds.), Field methods in cross-cultural psychology (pp. 137-164). Newbury Park, CA: Sage.

Burton, P. (2006). Easy prey: Results of the national youth victimisation study. SA Crime Quarterly, 16, 1-6.

Evans, S. E., Davies, C., \& DiLillo, D. (2008). Exposure to domestic violence: A meta-analysis of child and adolescent outcomes. Aggression and Violent Behavior, 13(2), 131-140.

Fehon, D. C., Grilo, C. M., \& Lipschitz, D. S. (2001). Correlates of community violence exposure in hospitalized adolescents. Comprehensive Psychiatry, 42(4), 283-290.

Fincham, D. S., Korthals Altes, L. K., Stein, D. J., \& Seedat, S. (2009). Posttraumatic stress disorder symptoms in adolescents: Risk factors versus resilience moderation. Comprehensive Psychiatry, 5o, 193-199.

Finkelhor, D., Ormrod, R. K., \& Turner, H. A. (2007). Polyvictimization: A neglected component in child victimization. Child Abuse \& Neglect, 31, 726. Finkelhor, D., Ormrod, R., Turner, H., \& Hamby, S. L. (2005). The victimization of children and youth: A comprehensive national survey. Child Maltreatment, 1O, 5-25.

Fowler, P. J., Tompsett, C. J., Braciszewski, J. M., Jacques-Tiura, A. J., \& Baltes, B. B. (2009). Community violence: A meta-analysis on the effect of exposure and mental health outcomes of children and adolescents. Development and Psychopathology, 21, 227-259.

Garrido, E. F., Culhane, S. E., Raviv, T., \& Taussig, H. N. (2010). Does community violence exposure predict trauma symptoms in a sample of maltreated youth in foster care? Violence and Victims, 25(6), 755-769. 
Hunt, K. L., Martens, P. M., \& Belcher, H. M. E. (2011). Risky business: Trauma exposure and rate of posttraumatic stress disorder in African American children and adolescents. Journal of Traumatic Stress, 24(3), 365369.

Jewkes, R., \& Abrahams, N. (2002). The epidemiology of rape and sexual coercion in South Africa: an overview. Social Science and Medicine, 55(7), 1231-1244.

Kaminer, D., Grimsrud, A., Myer, L., Stein, D., \& Williams, D. R. (2008). Risk for posttraumatic stress disorder associated with different forms of interpersonal violence in South Africa. Social Science and Medicine, 67, 1589-1595.

Kessler, R. C., Sonnega, A., Bromet, E., Hughes, M., \& Nelson, C. B. (1995). Posttraumatic stress disorder in the National Comorbidity Survey. Archives of General Psychiatry, 52(12), 1048-1060.

Kilpatrick, D. G., Ruggiero, K. J., Acierno, R., Saunders, B., Resnick, H., \& Best, C. (2003). Violence and risk of PTSD, major depression, substance abuse/dependence, and comorbidity: Results from the National Survey of Adolescents. Journal of Consulting and Clinical Psychology, 71(4), 692-700.

Lambert, S. F., Ialongo, N. S., Boyd, R. C., \& Cooley, M. R. (2005). Risk factors for community violence exposure in adolescence. American Journal of Community Psychology, 36(1), 29-48.

Little, R. J. A., \& Su, H. L. (1989). Item nonresponse in panel surveys. In D. Kasprzyk, G. Duncan, \& M. P. Singh (Eds.), Panel surveys (pp. 400-425). New York: Wiley.

Lozano, L. M., García-Cueto, E., \& Mum iz, J. (2008). Effect of the number of response categories on the reliability and validity of rating scales. Methodology, 4(2), 73-79.

Lund, C., Boyce, G., Flisher, A. J., Kafaar, K., \& Dawes, A. (2009). Scaling up child and adolescent mental health services in South Africa: Human resource requirements and costs. Journal of Child Psychology and Psychiatry, 5o(9), 1121-1130.

MacDonald, A., Kmett Danielson, C., Resnick, H. S., Saunders, B. E., \& Kilpatrick, D. G. (2010). PTSD and comorbid disorders in a representative sample of adolescents: The risk associated with multiple exposures to potentially traumatic events. Child Abuse \& Neglect, 34, $773-783$.

Madu, S. N., \& Peltzer, K. (2000). Risk factors and child sexual abuse among secondary school students in the Northern Province (South Africa). Child Abuse \& Neglect, 24(2), 259-268.

Malik, N. M. (2008). Exposure to domestic and community violence in a nonrisk sample: Associations with child functioning. Journal of Interpersonal Violence, 23, 490-504.

March, J. S., Amaya-Jackson, L., Terry, R., \& Costanzo, P. (1997). Posttraumatic symptomatology in children and participants after an industrial fire. Journal of the American Academy of Child and Adolescent Psychiatry, 36(8), 1080-1088. 
McCart, M. R., Smith, D. W., Saunders, B. E., Kilpatrick, D. G., Resnick, H., \& Ruggiero, K. J. (2007). Do urban adolescents become desensitized to community violence? Data from a national survey. American Journal of Orthopsychiatry, $77(3), 434-442$.

Mrug, S., Loosier, P. S., \& Windle, M. (2008). Violence exposure across multiple contexts: Individual and joint effects on adjustment. American Journal of Orthopsychiatry, 78, 70-84.

Okundaye, J. N. (2004). Drug trafficking and urban American youth: Risk factors for PTSD. Child and Adolescent Social Work Journal, 21, 285302. RAPCAN (2012). Crimes against children. Retrieved from http://www.rapcan.co.za

Rubin, D. B. (1987). Multiple imputation for nonresponse in surveys. New York: Wiley.

Seedat, M., Van Niekerk, A., Jewkes, R., Suffla, S., \& Ratele, K. (2009). Violence and injuries in South Africa: Prioritising an agenda for prevention. Lancet Special Issue: Health in South Africa, 20o9(August), 68-79.

Seedat, S., Nyamai, C., Njenga, F., Vythilingum, B., \& Stein, D. (2004). Trauma exposure and post-traumatic stress symptoms in urban African schools: Survey in Cape Town and Nairobi. British Journal of Psychiatry, 184, 169-175.

Seedat, S., van Noord, E., Vythilingum, B., Stein, D. J., \& Kaminer, D. (200o). School survey of exposure to violence and posttraumatic stress symptoms in adolescents. South African Journal of Child and Adolescent Mental Health, 12(1), 38-44.

Shields, N., Nadasen, K., \& Pierce, L. (2008). The effects of community violence on children in Cape Town, South Africa. Child Abuse \& Neglect, 32, 589601. Shields, N., Nadasen, K., \& Pierce, L. (2009). A comparison of the effects of witnessing community violence and direct victimization among children in Cape Town, South Africa. Journal of Interpersonal Violence, 24(7), 1192-1208.

South African Institute of Race Relations. (2004). South Africa Survey 2003/2004. Johannesburg: South African Institute of Race Relations.

South African Institute of Race Relations. (2011). South Africa Survey 2009/2010: Crime and security. Johannesburg: South African Institute of Race Relations. SPSS Inc. (2011). PASW Statistics (SPSS) version 19.o.o for Windows [Computer software]. Chicago: SPSS.

Statistics South Africa (2003). City of Cape Town Census 2001 - Langa. Retrieved from www.capetown.gov.za/en/stats/2001census/Documents/Langa.htm Suliman, S., Mkabile, S. G., Fincham, D., Ahmed, R., Stein, D. J., \& Seedat, S. (2009). Cumulative effect of multiple trauma on symptoms of posttraumatic stress disorder, anxiety and depression in adolescents. Comprehensive Psychiatry, 5O, 121-127.

Ikasi: The moral ecology of South Africa's township youth. New York: Palgrave MacMillan. 
Tabachnick, B. G., \& Fidell, L. S. (2007). Using multivariate statistics (5th ed.). New York: Allyn and Bacon. 